\title{
Conjunctive bias in memory representations of logical connectives
}

\author{
AARON RADER and VLADIMIR SLOUTSKY \\ Ohio State University, Columbus, Ohio
}

\begin{abstract}
The paper presents the conjunctive bias in memory-a novel phenomenon that helps to clarify representations of logical connectives. The conjunctive bias is a tendency toward more accurate recall and recognition of conjunctive forms than of forms based on other logical connectives and a tendency to recall and recognize other logical forms as if they were conjunctions. Three experiments, in which participants' memory representations associated with different logical connectives were examined, were conducted to test the conjunctive bias hypothesis. In Experiment 1, participants learned pictureproposition pairs involving either conjunctions or disjunctions and then had to recall each proposition when cued with its picture. In Experiments 2 and 3, recognition memory for conjunctions, disjunctions, and conditionals was examined with an old/new recognition procedure. The findings of these experiments provide evidence for the conjunctive bias. Furthermore, the results of Experiment 3 suggest that conjunctive bias is not simply a pragmatically caused preference for conjunctions. The discussion focuses on the implications of these findings for current theories of deductive reasoning.
\end{abstract}

Logical connectives are omnipresent in human life. For example, a person ordering fish and chips expects the server to bring the two things together. Even when presented with completely unfamiliar propositions (such as Blinker is either a gof or a juppet. Blinker is not a gof), most adolescent and adult participants infer that Blinker is a juppet (see Braine, Reiser, \& Rumain, 1984, and Evans, Newstead, \& Byrne, 1993, for reviews). Therefore, the processing of sentences with logical connectives cannot be solely a function of content and experience, and there must be more general mechanisms underlying the processing of these sentences. Furthermore, such processing is often linked to reasoning or deriving conclusions from these sentences.

The two major approaches attempting to explain the processing of logical connectives, including that in reasoning tasks, are the syntactic and the semantic. According to the syntactic approach, people extract and represent the logical form, or syntax, of statements that include logical connectives. According to the semantic approach, people represent possibilities consistent with a statement, although these representations may deviate from

This research was supported in part by a grant from the James S. McDonnell Foundation to the second author and by a Summer Fellowship awarded by the Center for Cognitive Science at Ohio State University to the first author. We thank Uri Hasson, Aaron Yarlas, Steven Sloman, and two anonymous reviewers for their helpful comments and suggestions. Correspondence concerning this article should be addressed either to A. W. Rader, Ohio State University, 21 Page Hall, 1810 College Road, Columbus, OH 43210 (e-mail: rader.34@ osu.edu), or to V. M. Sloutsky, Ohio State University, 21 Page Hall, 1810 College Road, Columbus, OH 43210 (e-mail: sloutsky.1@ osu.edu). logical prescriptions. These contrasting positions lead to different hypotheses about the nature of the representations of statements containing connectives, and these hypotheses are the subject of the present work.

Syntactic theories propose that an argument's logical form, with the form being defined according to standards of formal propositional logic, determines the deductive inferences of untrained reasoners (Braine \& O'Brien, 1998; Rips, 1994). A critical hypothesis of these theories is that reasoners abstract the logical form of arguments and, therefore, of constituent propositions. If the form matches one or more of several inference schemas stored in memory, the reasoner infers the conclusion licensed by the relevant schema(s). Several syntactic theorists have argued that some schemas are similar to grammatical frames, in that these schemas are applied in an online, obligatory fashion to linguistic input whenever premises are present together in working memory (Braine et al., 1984; Lea, 1995; Lea, O’Brien, Fisch, Noveck, \& Braine, 1990; but see Rips, 1994). Automatic application of inference schemas seems to imply that the abstraction of logical form should also be automatic.

The hypothesized inference schemas correspond to a subset of proof-theoretic deduction rules. For example, the argument Either Ted will run today or he'll go swimming; Ted won't run today matches a "disjunction elimination schema" that has the form A or B; not-A; therefore, $B$ (the relevant inference would be Ted will go swimming). Another example is the argument If Jane eats too much, she'll spoil her dinner; Jane ate too much. This argument matches the "modus ponens" schema, which has the form If A then $B$; $A$; therefore, $B$. The precise 
content of the statement is of secondary importance: The logical form should be abstracted regardless of content.

Critically, the assumption that untrained participants represent arguments in terms of their logical form requires that participants represent the logical syntax of each proposition in the argument (otherwise, the appropriate inference schemas cannot be applied). Thus, logical syntax must be extracted from the surface structure of statements. Reasoners should accurately represent disjunctions, conditionals, and conjunctions of the form $A$ and $B$ and some combinations of these three forms. Although errors may occur in translation from surface form to the deep logical form, these errors are not generally predicted to show systematic tendencies. Indeed, reasoning difficulty in syntactic theories is largely a function of the number of inference schemas that must be applied to a problem to evaluate a given conclusion, as well as the difficulty of each involved schema (Braine et al., 1984; Rips, 1994). This prediction about error rates, however, cannot be tested in the present experiments, because these experiments concern only initial representations of statements containing one logical connective and no conclusions were presented for evaluation.

The second major approach to the processing of propositions is the semantic approach, which is best represented by the mental models theory (Johnson-Laird \& Byrne, 1991). The mental models theory does not assume that untrained participants automatically parse propositions into proof-theoretic logical syntax. Instead, participants should represent various combinations of possibilities. They tend to represent only those possibilities that are explicitly mentioned and that are compatible with a statement if the statement is true (Evans \& Over, 1996; Johnson-Laird \& Byrne, 1991). Because participants are assumed not to represent what is false, even when false possibilities are prescribed by the propositional calculus, their representations may be logically incomplete.

For example, the initial representation of a conditional premise of the form If $A$ then $B$ will consist of a conjunction of antecedent and consequent:

a b

The "a" and " $b$ " are tokens corresponding to the propositions $A$ and $B$. They are written on a single line because they correspond to a single possibility, in which both $A$ and $B$ are true. The ellipsis on the second line corresponds to other possibilities consistent with the conditional that may be retrieved from memory (Byrne \& Tasso, 1999; Johnson-Laird, Byrne, \& Schaeken, 1992). However, these possibilities are not explicit and are often forgotten, in which case the representation is essentially a conjunction of antecedent and consequent. Logically, a conditional is also true whenever its antecedent is false (the conditional If $A$ then $B$ affords three true possibilities, $A \& B$, not- $A \&$ not $-B$, and not $-A \& B$ ), but neither nonexplicitly mentioned possibilities (e.g., not- $A \&$ not$B)$ nor false possibilities $(A \&$ not- $B)$ are represented.
The initial representation for a disjunction of the form $A$ or $B$ is similarly logically incomplete:

a

b

Here, "a" and "b" are written on separate lines because each denotes one possibility: "a" denotes a possibility in which $A$ is true, and " $b$ " denotes the converse possibility (see Johnson-Laird et al., 1992, p. 424). Nothing else would be represented (e.g., a token corresponding to not$B$ when $A$ is true in the above disjunction), because nothing else is stated. Disjunction is formally inclusive, so a third possibility ( $A$ and $B$ are both true) is consistent with the disjunction. However, that possibility is not explicitly given.

Finally, a conjunction of the form $A$ and $B$ yields this representation:

a b

A conjunction is only compatible with one possibility, because both conjuncts must be true for it to be true; furthermore, both conjuncts are explicitly stated. The mental models theory proposes that reasoners may "flesh out" initial representations to be complete and logically veridical but that this process often will not happen, because reasoners prefer to represent explicitly as little as possible (Johnson-Laird \& Byrne, 1991). In addition, the fleshing-out process is tied to the process of deliberate reasoning. Upon constructing an initial representation, reasoners combine premise representations and search for a nonrepetitive conclusion; once a candidate conclusion is found, reasoners search for counterexamples to it. Only those conclusions for which no counterexamples are found will be accepted. However, these processes seem to come into play only when participants are asked to reason, and not always even then (Evans, 2000; Evans, Handley, Harper, \& Johnson-Laird, 1999; Johnson-Laird, Savary, \& Bucciarelli, 2000; Polk \& Newell, 1995), and therefore, will not be further considered here.

Syntactic and semantic theories make different predictions about what is represented when a person processes a proposition with a logical connective, and a convenient way of examining these representations is to study memory for propositions with different logical connectives. According to the syntactic theory, participants should veridically represent the logical syntax of the proposition (except for random comprehension errors), whereas the semantic theory predicts that people should represent possibilities compatible with the proposition. Because they typically do not represent all of these possibilities (Johnson-Laird \& Byrne, 1991), propositions that are compatible with multiple possibilities, such as disjunctions and conditionals, should elicit more representational errors than do propositions that are compatible with a single possibility, such as conjunctions. Indeed, one recurrent finding in research into reasoning is that as the number of possibilities increases, participants' error rates also increase (see Johnson-Laird, 1999, for a review). 
Multiple lines of evidence are consistent with semantic predictions. Some findings suggest that, across different propositional forms-such as conjunctions, inclusive disjunctions, conditionals, and biconditionalspeople tend to represent one possibility by conjoining what is asserted in both atomic statements (Sloutsky \& Goldvarg, 1999). For example, a conditional statement, such as If Bill goes fishing, he'll miss the game, is represented as Bill goes fishing and he misses the game. By committing this "conversion to conjunction," participants typically fail to consider other true possibilities, such as the negation of both constituent propositions in the conditional (Sloutsky \& Goldvarg, 1999).

The relative difficulty in reasoning with disjunctions, as compared with the relative ease in reasoning with conjunctions, is another type of supporting evidence for the semantic approach. Conjunctions are associated with almost no reasoning errors and no systematic error patterns (Braine et al., 1984; Rips, 1994), but reasoning from disjunctive premises is associated with many errors. Errors seem to stem from a failure to represent all the possibilities consistent with the premises (Evans et al., 1993; Johnson-Laird et al., 1992; Klauer \& Oberauer, 1995). In addition, if reasoners are provided with external aids that allow possibilities to be represented visually, performance with disjunctions improves, as semantic views predict (Bauer \& Johnson-Laird, 1993; Sloutsky \& Goldvarg, 1999).

Finally, some evidence indicates that the frequent occurrence of errors when reasoning with conditionals (e.g., Byrne \& Tasso, 1999; Evans, Clibbens, \& Rood, 1995; Evans et al., 1993) and processing conditional premises (Rader \& Sloutsky, in press) stems from a failure to represent all the possibilities. For example, reasoners endorse the valid conditional arguments of modus ponens (If $A$ then $B ; A$; therefore, $B$ ) and modus tollens (If $A$ then $B$; not-B; therefore, not- $A$ ), but they also tend to endorse the invalid forms of affirming the consequent (If $A$ then $B ; B$; therefore, $A$ ) and denying the antecedent (If $A$ then $B$; not-A; therefore, not-B). They also tend to draw both valid modus ponens inferences and invalid affirming-the-consequent inferences in the course of comprehension (Rader \& Sloutsky, in press). These data imply that participants tend to represent the conditional as a conjunction of antecedent and consequent. A syntactic explanation of these phenomena might be that reasoners interpret the conditional biconditionally, drawing the "invited inference" that If $A$ then $B$ implies If $B$ then $A$ (Braine \& O'Brien, 1991). However, this hypothesis has not been supported empirically (Rader \& Sloutsky, in press).

On the basis of these considerations, we suggest that untrained participants may exhibit a conjunctive bias that affects their representations of binary propositional forms. That is, when presented with memory tasks, participants may tend to represent in memory only the conjunction of a proposition's atomic constituents. In this case, conjunctions should be remembered more accurately than other propositional forms, and other forms should tend to be converted to conjunctions. Syntactic theories make no such a priori predictions. Because untrained participants should possess inference schemas that involve and, or, and if (Braine et al., 1984; Rips, 1994), all propositions involving these schemas should generate similar error rates. Syntactic theories should not be construed as predicting perfect performance, of course. They do not predict, however, any systematic differences in recall or recognition performance with the logical forms used in the experiments reported below.

Predictions of the conjunctive bias hypothesis were tested in three experiments using different memory paradigms. In Experiment 1, participants learned pictureproposition pairs and then had to recall each proposition when cued with its picture. Conjunctions and disjunctions were the critical propositional forms used in this experiment. It was predicted that conjunctions would be better recalled than disjunctions. In addition, recall errors that were consistent with a change of propositional logical form were hypothesized to be less likely with conjunctions than with disjunctions. This type of error, termed a conversion, would occur if both atomic propositions were recalled correctly but the connective linking them was not, so that, for example, and was substituted for $o r$. As a result, disjunctions should be more frequently represented (and thus recalled) as conjunctions; conjunctions should less frequently be recalled as disjunctions.

Experiments 2 and 3 tested the conjunctive bias hypothesis by examining recognition memory for conjunctions, disjunctions, and conditionals, using an old/new recognition procedure. It was predicted that recognition performance would be analogous to recall: Participants should correctly accept conjunctions as old, and should correctly reject foils with the same content (i.e., same atomic propositions) but wrong connectives as new. Performance with disjunctions and conditionals should be poorer: The tendency to accept original statements as old should be less prominent, and the tendency to accept conjunctive foils as old should be greater.

\section{EXPERIMENT 1}

Experiment 1 used a paired-associate procedure to compare recall and conversion rates for conjunctions and disjunctions. Each participant received the same number of learning trials with a set of propositions created from randomly paired atomic statements; atoms were paired randomly to minimize any systematic differences among propositional forms in their meaningfulness or acceptability.

\section{Method}

Participants. Forty-nine undergraduate participants (35 women and 14 men) from a large Midwestern university took part in the study. Some volunteered in return for extra course credit, whereas others were paid a small cash amount for participation.

Materials. A set of 18 pictures and 18 propositions was used in the experiment. Each picture, printed on plain white paper and laminated, measured approximately $4 \times 5$ in. and depicted a black-and- 
white line drawing of a face. Each proposition was a description of a college professor and began with the phrase This professor... The propositions were printed, in 14-point type, on slips of paper that measured about $2.5 \times 8$ in. and that were laminated.

Descriptions were created by first generating a list of 50 atomic statements. Each statement involved simple verb-object syntax (e.g., has a cat, drinks coffee ). For each compound proposition, two statements were selected randomly. Once six pairs of propositions had been selected in this way, logical forms (conjunction or disjunction) were assigned to them randomly. Another six statements were chosen randomly for use as atomic propositions (three affirmations and three negations), with affirmative and negative forms assigned randomly. In addition, another six statements were chosen for the creation of tautologies and contradictions, which were included for separate purposes from those of this paper. The three conjunctions and disjunctions are presented in Appendix A.

Design and Procedure. The experiment included the withinsubjects factors of propositional form (conjunction or disjunction) and learning trial. For each participant, the picture-description pairs were randomly determined, so that every participant received a unique pairing of pictures and descriptions. All the participants were tested individually in a 30 to 40 min session, seated at a small table across from the experimenter. The procedure was videotaped for subsequent analyses.

The experiment consisted of five learning trials, with each trial consisting of 18 picture-description pairs presented for learning and 18 pictures presented for cued recall. The pairs were presented one at a time, with the experimenter placing one picture-description pair on the table in front of the participant. The participant read the description aloud. As soon as she finished, the experimenter removed the picture-description pair from the table and presented the next pair for the participant to read. The 18 pairs were presented in a different random order for each learning trial and each participant. After all 18 pairs had been presented, the experimenter re-presented just the pictures, one at a time. Order of picture presentation was also randomized for each participant and each trial. The participant was instructed to recall the description paired with each picture. On each trial, only those responses that recalled descriptions word for word were judged correct. Following the last (i.e., fifth) learning trial, the experimenter debriefed the participant.

\section{Results and Discussion}

For all the analyses reported in this and subsequent experiments, within-subjects effects in analyses of variance (ANOVAs) were evaluated, using the GeisserGreenhouse correction when necessary. In addition, all post hoc pairwise comparisons reported were evaluated, using the Bonferroni correction for multiple comparisons.

The numbers of items correctly recalled, as a function of trial and propositional form, are presented in the top half of Figure 1. A repeated measures ANOVA, using these within-subjects factors, found main effects for propositional form $\left[F(1,48)=10.96, M S_{\mathrm{e}}=1.1, p<\right.$ $.001]$ and for trial $\left[F(4,192)=137.6, M S_{\mathrm{e}}=0.61, p<\right.$ $.0001]$. The main effect of form indicates that conjunctions $(M=38 \%, S E=2.4 \%)$ were accurately recalled more often than disjunctions $(M=27.5 \%, S E=2.4 \%)$. The main effect of trial (memory improved across trials) is to be expected. The trial $\times$ form interaction was also significant $\left[F(4,192)=3.42, M S_{\mathrm{e}}=0.46, p<.05\right]$. Simple effects analyses that compared correct recall rates by form for each trial found that correct recall rates for conjunctions were significantly higher than those for con-
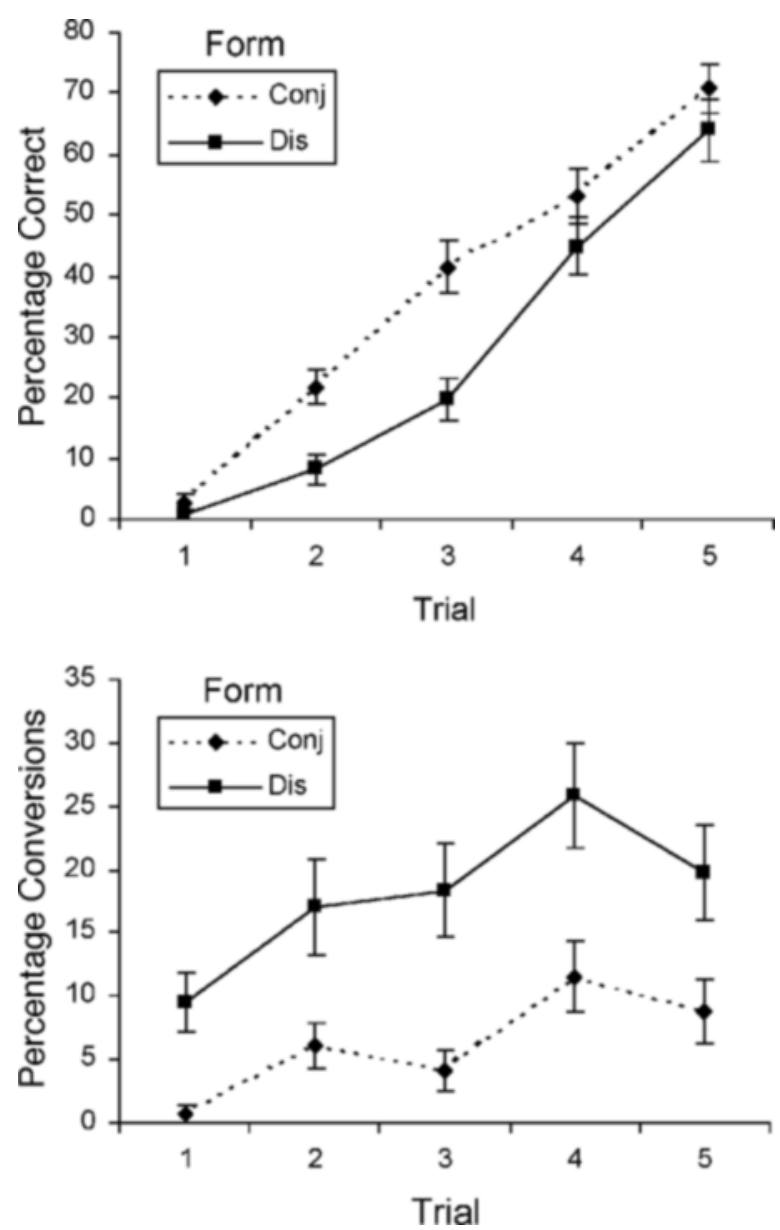

Figure 1. Mean percentages of correct recall and of conversions $( \pm S E)$ by propositional form and trial, Experiment 1 .

junctions on Trials 2 and $3\left[F_{\mathrm{s}}(1,48)=14.08\right.$ and 18.20 , respectively, $p s<.001]$. On all other trials, differences were in the predicted direction, but not significant.

A second set of analyses focused on the number of conversions by trial and propositional form, and these data are presented in the bottom half of Figure 1. A repeated measures ANOVA, using these factors, found main effects for propositional form $[F(1,48)=24.35$, $\left.M S_{\mathrm{e}}=0.63, p<.001\right]$ and for trial $[F(4,192)=7.85$, $\left.M S_{\mathrm{e}}=0.33, p<.001\right]$. As Figure 1 suggests, conjunctions $(M=6.3 \%, S E=1.2 \%)$ were significantly less likely to be converted than were disjunctions $(M=$ $18.1 \%, S E=2.1 \%)$. The form $\times$ trial interaction was not significant $[F(4,192)<1]$. Again, the main effect of trial indicates that conversions grew across trials, which is to be expected, because a proposition cannot be converted if it is not recalled at all.

The data are consistent with the predictions. Conjunctions were more likely to be recalled veridically and were less likely to be converted than were disjunctions. 
The paired-associate procedure had some liabilities, however. The participants needed to encode information about the faces, as well as the descriptions, and conversions may have stemmed from the participants' tendency to simplify the task. In addition, the procedure required multiple learning trials, but the conjunctive bias hypothesis also pertained to initial representations formed when a proposition was first processed. Because learning rates per se are not of primary interest, a procedure that could bypass the use of repeated trials is desirable. Finally, there were very few stimuli for each logical form. The following experiment, focusing on recognition rather than recall, attempted to address these shortcomings, as well as to look at accuracy and conversions for an additional logical connective.

\section{EXPERIMENT 2}

In this experiment, the participants' recognition memory for compound propositional forms was examined in an old/new recognition procedure. In the study phase, the participants read descriptions displayed on a computer screen one at a time and were tested for recognition afterward. In the recognition phase, descriptions were displayed one at a time on screen, and the participants decided for each whether it was old (already presented) or new. The test descriptions included the original descriptions (targets), as well as foils in which only one or two words were changed from the original. In some cases, the word changed was the logical connective linking the atomic propositions. For other foils, the connective was changed to a nonlogical connective unused in the original descriptions, and for the rest of the foils, a noun in one of the atomic propositions was changed, thus changing content, but not logical form.

The compound propositional forms examined were conjunctions, disjunctions, and conditionals. Conditionals were included in Experiment 2 to extend the test of the conjunction bias hypotheses to a third logical form. Recall that according to the conjunctive bias hypothesis, representations of conditionals should be confused with those of conjunctions, but the reverse type of confusion should occur less frequently.

\section{Method}

Participants. Twenty-nine undergraduates from a large Midwestern university completed the experiment for course credit. Two participants were dropped from analyses after telling the experimenter that they had not followed instructions, and 2 were dropped because their data revealed that each accepted approximately $50 \%$ of all types of test items, even those that were checks on random responding (see below). The final sample thus included 25 participants (13 women and 12 men).

Materials. The initial list included 45 compound propositions, or original descriptions, with 15 each in the forms of conjunction, disjunction, and conditional. These propositions were presented as descriptions of hypothetical people (each description began with the phrase This person). The propositions were constructed in the same manner as in Experiment 1, except that the initial pool consisted of 150 atomic propositions, most of which were not used in previous experiments. Appendix B contains the complete list of original descriptions.

The recognition test included 225 test descriptions. Included on the test were the original 45 targets, along with 180 foils; 4 foils were based on each target. Two of these foils, the different-form foils, presented the content of the original in the other two logical forms (e.g., a conjunction target would have disjunction and conditional different-form foils). A 3rd foil, the different-noun foil, altered one noun in one atomic proposition from the original target. For these foils, a noun was changed into another one that was semantically sensible for that atomic proposition's verb. Finally, the different-connective foil changed the connective to a nonlogical connective ("nonlogical" in that these connectives are not the basic connectives of formal propositional logic but are considered natural-language equivalents of these connectives). For these foils, the nonlogical connectives used were but, unless, and whenever. Each nonlogical connective was used with five of the original descriptions of each propositional form, and assignment of these connectives to descriptions was random. All the original and test descriptions were presented on a computer screen in 18-point type.

The targets and different-form foils are of primary interest because hypotheses concern participants' abilities to discriminate the targets of each propositional form from these distractors. The different-noun and different-connective foils were included primarily as checks on random responding. The different-connective foils used connectives that never appeared on the initial list and, consequently, should not have been selected. The different-noun foils changed the meaning of each proposition at a relatively gross level. Recognition studies of sentence memory indicate that participants reliably detect such semantic changes (Begg \& Wickelgren, 1974; Dosher, 1983; Sachs, 1974); it was thus reasonable to expect that participants would rarely select these foils.

Design and Procedure. The presentation of items and the recording of the participants' responses was controlled by an IBMcompatible computer running the program SuperLab, Version 1.05 (SuperLab Pro, 1997). The primary variables, both manipulated within subjects, were the original form of the description (conjunction, disjunction, conditional) and the test form of the description (conjunction, disjunction, conditional). The dependent measure was the acceptance rate for test descriptions in each original-test combination. When the original and the test forms coincide, the test description is a target, and acceptance of it constitutes a hit. When the original form and the test form differ, the test description is a foil, and acceptance of it is a false alarm. Differences between hit and false alarm rates measure the ability to discriminate targets from different-form foils.

Each participant was tested individually. Instructions informed the participant that he or she would see a series of one-sentence descriptions of people, one at a time. The instructions advised the participant to study the descriptions carefully, because memory for the descriptions would be tested after they all had been presented. The instructions also advised the participant not to be concerned if some of the descriptions seemed odd or unusual, but simply to study them carefully. During presentation of these instructions, the experimenter went over them with the participant and answered any questions.

Following these instructions, the initial list was presented. Each description was presented by itself, centered, onscreen. The word READY appeared for $500 \mathrm{msec}$ in the center of the screen to draw the participant's attention. This cue disappeared, and the description appeared for $10 \mathrm{sec}$. The description then disappeared, and the process repeated for the next description. Order of presentation was randomized by the program for each participant.

After the last description was presented, another set of instructions appeared on screen. These instructions informed the participant that he or she would see another series of descriptions, one at a time. For each description, the participant was to press the " $Z$ " key if he or she believed that it had been presented previously, and 
he or she was to press the "M" key if he or she believed it to be new. The instructions stated explicitly that the participant should only respond with old to descriptions that he or she believed matched the original descriptions exactly, word for word. The participant was then instructed to place one finger each on the "Z" and " $M$ " keys for the duration of the experiment. The participant then made old/new decisions for each of the 225 test descriptions. The participant's response to one description cleared the screen and displayed the next description. One description appeared at a time, with each centered on screen. Order of presentation of test descriptions was randomized for each participant by the program.

\section{Results and Discussion}

It is clear that most of the participants took the task seriously, in that acceptance rates for the different-noun and different-connective foils were quite low. Mean acceptance rates of different-noun and different-connective foils for conjunctions, disjunctions, and conditionals ranged from $2 \%$ to $14 \%$. Because these items were intended as controls and were accepted so infrequently, they were dropped from further analysis. Mean acceptance rates for the critical test descriptions are presented in Figure 2. A 3 (original form) $\times 3$ (test form) ANOVA on the numbers of acceptances, with repeated measures on both factors, found a significant effect of test form $\left[F(2,48)=20.22, M S_{\mathrm{e}}=20.23, p<.001\right]$. The original form $\times$ test form interaction was also significant $\left[F(4,96)=20.22, M S_{\mathrm{e}}=9.43, p<.001\right]$. The effect of original form was not significant $[F(2,48)=1.42, p=$ .25].

Simple effects analyses examined the interaction through comparisons of acceptance rates for the test forms within each original form. For all three analyses, the omnibus tests were significant $\left[F_{\mathrm{s}}(2,48)>5, p \mathrm{~s}<\right.$ $.01]$. Pairwise comparisons of means were conducted after each omnibus test, and the results are noted in Figure 2. As the figure indicates, for original conjunctions, conjunction targets $(M=64.8 \%, S E=4.5 \%)$ were accepted significantly more often than disjunction foils $(M$ $=37.3 \%, S E=5.1 \%)$, which were accepted more often than conditional foils $(M=21.1 \%, S E=3.5 \%)$. For original disjunctions, acceptance rates for disjunction targets $(M=59.5 \%, S E=4.8 \%)$ and conjunction foils $(M=50.4 \%, S E=3.9 \%)$ did not differ significantly, although both were accepted more often than conditional foils $(M=21.1 \%, S E=3.0 \%)$. Finally, for original conditionals, the acceptance rate for conditional targets $(M=$ $42.4 \%, S E=4.0 \%$ ) was slightly, although nonsignificantly, lower than the acceptance rate for conjunction foils $(M=52.8 \%, S E=4.4 \%)$. However, conjunction foils were more likely to be accepted than were disjunction foils $(M=32.0 \%, S E=4.9 \%)$.

In the case of the effect of test form, post hoc pairwise comparisons found that test items that were conjunctions were significantly more likely to be accepted $(M=$ $56.0 \%, S E=3.4 \%$ ) than were test items that were disjunctions $[M=42.9 \%, S E=4.4 \% ; F(1,24)=6.04, p<$ $.05]$. Also, both conjunction test items and disjunction items were significantly more likely to be accepted than were conditional items $\left[M=28.2 \%, S E=2.9 \% ; F_{\mathrm{s}}(1,24)=\right.$ 64.85 and $12.59, p s<.005$, respectively].

The original form $\times$ test form interaction is critical because it is consistent with predictions of the conjunctive bias hypothesis. The participants readily discriminated original conjunctions from disjunctive and condi-

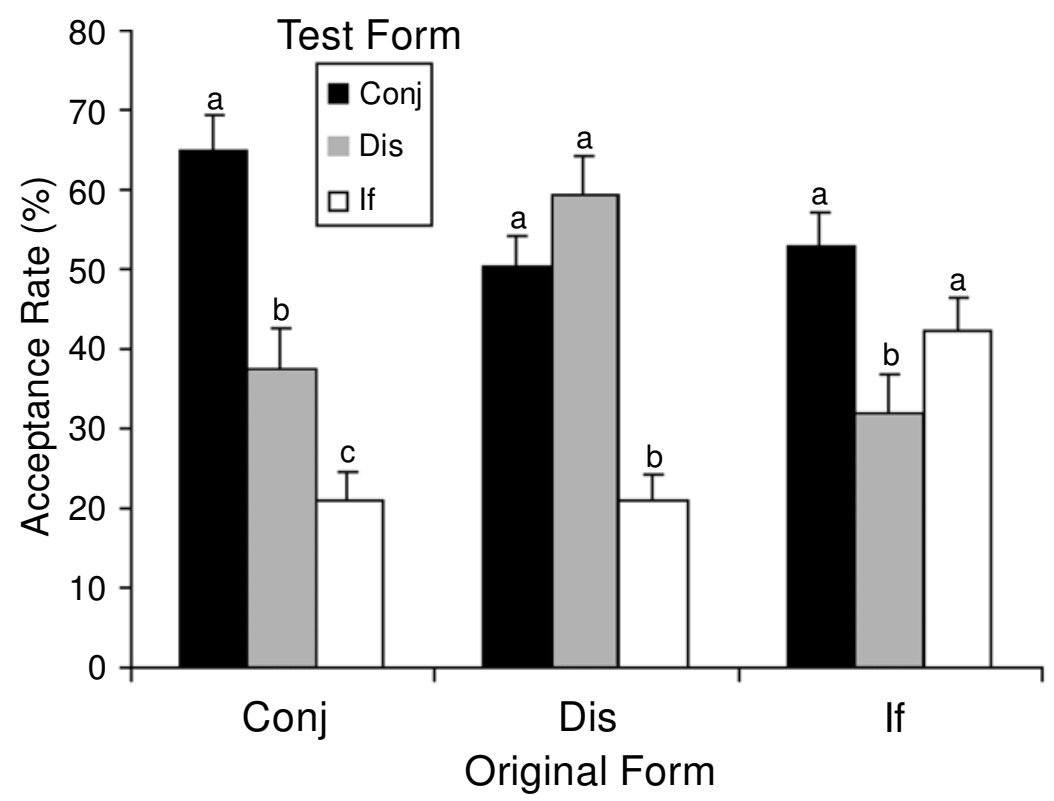

Figure 2. Mean acceptance rates $(+S E)$ by original propositional form and test propositional form, Experiment 2. Within each original form, means that do not share letters differ at $p<.01$ in Bonferroni-adjusted contrasts. 
tional foils (the participants were much more likely to accept as old those exact descriptions than they were to accept disjunction and conditional foils). At the same time, the participants poorly discriminated original disjunctions and conditionals from conjunctive foils (they were equally likely to accept the originals and their conjunction foils). Also, as is indicated by the effect of test form, the participants were more likely to accept conjunction test descriptions than disjunction test descriptions, and both of these items were accepted more often than were conditional test descriptions.

The results from this experiment corroborate the findings of Experiment 1. In cued recall, conjunctions were more likely to be recalled veridically than disjunctions and were less likely than disjunctions to be converted. In this recognition experiment, conjunction targets were accepted more often than disjunction targets and conditional targets, and the participants more easily avoided different-form foils with conjunctions than they did with disjunctions and conditionals. The tendency to false alarm on conjunction foils corresponds to the conversionto-conjunction tendency found in the cued-recall experiments. At the same time, the participants did show some ability to distinguish disjunctions and conditionals from each other. This finding is not critical to the conjunctive bias hypothesis, however, because the hypothesis pertains to the comparison of conjunctions with each form separately.

Experiment 2 does not eliminate an alternate hypothesis: Conjunctions may be more preferable than other logical forms and, therefore, more likely to be endorsed at the time of test. Some pragmatic arguments have advanced the hypothesis that conjunctions are more likely to be appropriate in discourse than are disjunctions (e.g., Fillenbaum, 1974a, 1974b; Lakoff, 1971). If this is true, the conjunctive bias may reflect conjunctions' greater plausibility/sensibility, rather than how different propositional forms are represented in memory.

In Experiment 3, another recognition study, these alternatives were examined in two ways. First, the recognition test included a set of completely new conjunctions, disjunctions, and conditionals, none of which was presented during learning. If conjunctions are more preferable, the participants should be more likely to accept new conjunctions than the other new propositions. Second, we collected sensibility ratings of some of the experimental stimuli. The ratings can be used to examine the acceptance rates of target items after variance owing to sensibility is removed. If acceptance rates are driven by sensibility, an analysis of covariance (ANCOVA), using these ratings as the covariate, should show no differences in acceptance rates across forms. As a third methodological note, this experiment rotated common content across different propositional forms; thus, the same content was presented in all three forms during learning (each participant received only one form during learning, but all three during test). This rotation was included in order to eliminate possible systematic effects of content on recognition of logical connectives.

\section{EXPERIMENT 3}

\section{Method}

Participants. A total of 33 introductory psychology undergraduates, including 24 women and 9 men, took part voluntarily in partial fulfillment of a course requirement.

Materials. The study utilized a total of 60 compound propositions (descriptions similar to those of Experiment 2) consisting of conjunctions, disjunctions, and conditionals, with 20 items of each form. Prior to the experiment, these items were given to a second group of 20 undergraduates. These participants rated the sensibility of these items on a 5-point scale (specifically, how sensible each would be as a description of a person), with a 5 representing the highest sensibility. To encourage the participants to use all the points on the scale, this rating survey also included conjunctions, disjunctions, and conditionals that were pragmatically sensible and some that were pragmatically incoherent (e.g., Fillenbaum, 1974a, 1974b; Lakoff, 1971; Schmerling, 1975). After ratings were collected, 30 of these propositions- 10 conjunctions, 10 disjunctions, and 10 conditionals - were randomly selected to be new propositions. These new items were presented only during the test phase of the experiment, and not during learning.

The remaining 30 rated descriptions were selected for use as critical descriptions. Critical descriptions were presented during learning. Each description was presented as a conjunction, a disjunction, and a conditional, although each participant received only one version of each. There were thus three groups of participants $(n=11$ per group), with the precise form of proposition used cycled across the participant groups. This procedure allowed each item to serve either as a target or as a foil to a target of a given form, depending on participant group.

During the learning part of the experiment, each participant saw one version of each of the 30 critical descriptions; the participants saw 10 of each form. During the test phase, a total of 120 test descriptions were presented: the 30 new items, and all 3 versions of each critical description (thus, one target item and two differentform foils for each).

Design and Procedure. The experimental design included the factors of original form (conjunction, disjunction, conditional) and test form (conjunction, disjunction, conditional). Also, the numbers of new descriptions accepted by each participant were analyzed in a one-way repeated measures design, with propositional form as a factor. Finally, the sensibility ratings allowed a comparison of acceptance rates for 10 each of the critical conjunctions, disjunctions, and conditionals, with sensibility as a covariate (these 30 items had been on the sensibility rating survey). The procedure was identical to that of Experiment 2.

\section{Results and Discussion}

The sensibility ratings gathered in the preliminary survey were compared with the acceptance rates for the 30 critical descriptions that were included on the survey. These items' mean sensibility ratings were moderately correlated with their acceptance rates in the recognition $\operatorname{task}\left[r(28)=0.43, p<.05\left(r^{2}=.19\right)\right]$. Furthermore, the mean sensibility ratings for these conjunctions $(M=$ $2.81, S E=0.19)$, disjunctions $(M=2.27, S E=0.16)$, and conditionals $(M=2.04, S E=0.18)$ were significantly different in a one-way ANOVA $[F(2,27)=5.02$, $\left.M S_{\mathrm{e}}=0.31, p<.05\right]$. We thus compared mean accep- 
tance rates for these conjunctions, disjunctions, and conditionals in an ANCOVA that used each item's mean sensibility rating as the covariate and propositional form as the between-groups factor. The results of this analysis indicated that, with variance owing to sensibility ratings removed, significant differences in mean acceptance rates existed $\left[F(2,26)=6.49, M S_{\mathrm{e}}=2.73, p<.01\right]$. Followup comparisons of the ANCOVA-adjusted means indicated that the acceptance rate for conjunctions $(M=$ $87.3 \%, S E=5.8 \%$ ) was significantly greater than the acceptance rate for conditionals $(M=56.3 \%, S E=$ $5.6 \%, p<.005)$. No other differences were significant, with the acceptance rate for disjunctions $(M=71.4 \%, S E=$ $5.3 \%$ ) falling between the other two. Note that these adjusted means are very close to the unadjusted mean acceptance rates for conjunctions, disjunctions, and conditionals $(89 \%, 71 \%$, and $55 \%$, respectively). Thus, although conjunctions were more sensible than the other forms, sensibility accounts for a very small proportion of variance in the participants' performance in the memory task. The conjunctive bias, therefore, appears robust with respect to conditionals and persists, to some extent, with disjunctions as well.

The acceptance rates for new descriptions were also analyzed in a one-way repeated-measures ANOVA, with propositional form as a factor. Acceptance rates for new conjunctions $(M=4.8 \%, S E=1.7 \%)$, new disjunctions $(M=2.7 \%, S E=1.0 \%)$, and new conditionals $(M=$ $2.4 \%, S E=1.1 \%$ ) were all very low. Not surprisingly, these rates were not significantly different from one another $[F(2,64)=1.61, p>.20]$. It should be noted that 18 participants rejected all of these foils and that much of the conjunction mean derives from 1 participant who accepted five new conjunctions. When that participant is removed, the mean conjunction acceptance rate drops to $3.4 \%$. These acceptance rates are so low, and the differences so small, that the preference hypothesis (i.e., participants simply prefer conjunctions, as compared with other forms, in memory tasks) does not seem to accrue much support.

Finally, acceptances of critical test descriptions for each original form and test form were analyzed in repeated measures ANOVAs, with original form and test form as factors. The participants' acceptance rates for test propositions of each type are shown as percentages in Figure 3. One analysis was collapsed over items to examine the number of acceptances by each participant in each condition ( $F_{1}$ analysis), and the second analysis was collapsed over participants to examine the number of acceptances to each test proposition in each condition $\left(F_{2}\right.$ analysis). These analyses revealed a significant effect of original form $\left[F_{1}(2,64)=3.65, M S_{\mathrm{e}}=2.72, p<.05\right.$, and $\left.F_{2}(2,58)=4.27, M S_{\mathrm{e}}=2.44, p<.05\right]$. The effect of test form was also significant, $\left[F_{1}(2,64)=4.40, M S_{\mathrm{e}}=\right.$ $11.37, p<.05$, and $F_{2}(2,58)=17.82, M S_{\mathrm{e}}=2.91, p<$ $.001]$. Finally, the original form $\times$ test form interaction was also significant, $\left[F_{1}(4,128)=30.08, M S_{\mathrm{e}}=4.07, p<\right.$ .001 , and $\left.F_{2}(4,116)=28.43, M S_{\mathrm{e}}=3.42, p<.001\right]$.

The original form $\times$ test form interaction is most significant for our hypotheses; it was examined via simple effects analyses that compared acceptance rates for the three test forms at each level of original form. All omnibus simple effects analyses were significant $\left[F_{1} \mathrm{~s}(2,64)>\right.$ $\left.8.4, p \mathrm{~s}<.005 ; F_{2} \mathrm{~s}(2,58)>13.5, p \mathrm{~s}<.001\right]$, so follow-up comparisons were conducted, and the results are noted in Figure 3 . As the figure indicates, with original conjunc-

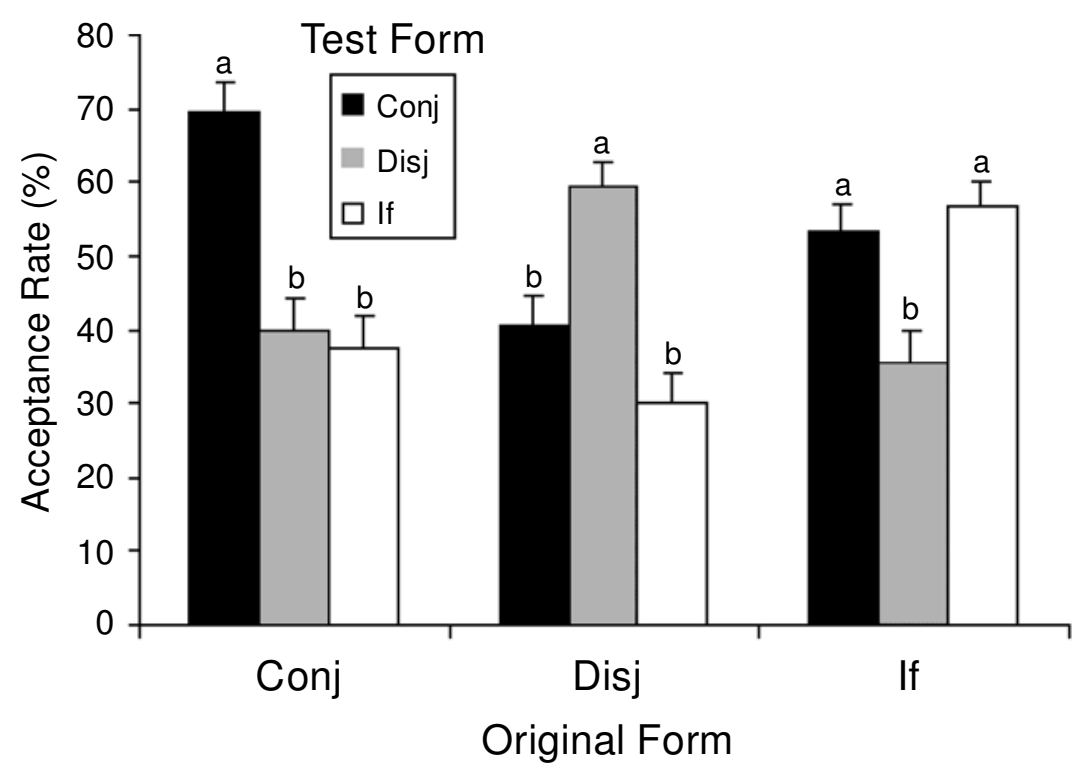

Figure 3. Mean acceptance rates $(+S E)$ by original propositional form and test propositional form, Experiment 3. Within each original form, means that do not share letters differ at $p<.005$ in Bonferroni-adjusted contrasts, in both $F_{1}$ and $F_{2}$ analyses. 
tions, target items were accepted significantly more often than both disjunction foils and conditional foils. Acceptance rates for disjunction and conditional foils did not differ. With original disjunctions, acceptance rates for targets were significantly greater than those for both conjunction and conditional foils. The participants showed a tendency to accept conjunction foils more often than conditional foils, $\left[F_{1}(1,32)=3.58, p=.07\right.$; $\left.F_{2}(1,29)=7.68, p<.05\right]$. Finally, with original conditionals, both targets and conjunction foils were accepted more often than disjunction foils. However, acceptance rates for targets and conjunction foils did not differ. Therefore, similar to Experiment 2, the participants readily discriminated conjunctive targets from disjunctive and conditional foils, although failing reliably to discriminate conditional targets from conjunctive foils. Discrimination of disjunctive targets from conjunctive foils was also somewhat lower than discrimination of conjunctive targets from disjunctive foils.

This experiment further supports the hypothesis of a conjunctive bias in memory for logical connectives. Furthermore, the bias does not seem to consist only of a preference for conjunctions in these memory tasks, nor does it appear only because conjunctions are more sensible. Also, with content rotated across propositional forms, the findings are similar to those of Experiment 2 . Conjunctions are readily discriminated from disjunctive and conditional foils. However, conditionals are poorly discriminated from conjunctive foils, suggesting that the former are frequently represented as the latter. Finally, although disjunctive targets were accepted more frequently than conjunctive foils, this target-foil difference was approximately $10 \%$ smaller than the difference found between conjunctive targets and disjunctive foils. The introduction of a more rigorous design, in which content was rotated over forms, may have contributed to the findings with disjunctive targets.

\section{GENERAL DISCUSSION}

The general hypothesis underlying the research reported here was that untrained participants should exhibit a conjunctive bias in their representations of binary propositional forms, such as conjunctions, disjunctions, and conditionals. Participants should tend to represent only the conjunction of a proposition's atomic constituents. In this case, if presented with a memory task, conjunctions, which are compatible with one possibility, should be remembered more accurately than other propositional forms, such as disjunctions and conditionals, which are compatible with multiple possibilities, and disjunctions and conditionals should tend to be converted to conjunctions. This hypothesis is compatible with semantic (i.e., mental models theory) claims that (1) people represent propositions in terms of corresponding possibilities, (2) these representations may be incomplete, because representations tend to include only what is explicitly stated (Johnson-Laird \& Byrne, 1991), and (3) they often represent only one possibility, in which both atomic propositions are true (Sloutsky \& Goldvarg, 1999). At the same time, the hypothesis runs counter to syntactic reasoning theories suggesting that participants represent the binary forms of conjunction, disjunction, and conditional in terms of their propositional syntax (Braine \& O'Brien, 1998; Braine et al., 1984; Rips, 1994).

The hypothesis was motivated by research into propositional reasoning showing that conditionals and disjunctions are associated with inference patterns that suggest incomplete problem representations (Bauer \& Johnson-Laird, 1993; Evans et al., 1995; Evans et al., 1993; Johnson-Laird et al., 1992; Klauer \& Oberauer, 1995; Rader \& Sloutsky, in press), whereas no such patterns are associated with conjunctions (Braine et al., 1984; Rips, 1994; Sloutsky \& Goldvarg, 1999).

The reported experiments supported the hypothesis with different research paradigms. In Experiment 1 (an examination of cued recall), conjunctions were recalled better and were associated with fewer conversion errors than were disjunctions. In the recognition tasks of Experiments 2 and 3, the participants could reliably discriminate conjunction targets from disjunctive and conditional foils that had the same content as the targets. However, in Experiment 2, neither disjunction targets nor conditional targets could reliably be discriminated from conjunction foils with the same content as these targets. Experiment 3 repeated these results with conditionals, although disjunction targets were accepted more often than conjunctive foils. Procedural changes between the two experiments may account for part of this difference. However, even in Experiment 3, the discrimination of disjunctive targets from conjunctive foils was approximately $10 \%$ smaller than the discrimination of conjunctive targets from disjunctive foils. In short, the recognition results mirror the conversion-to-conjunction tendency found with disjunctions in recall and suggest that the conjunctive bias extends to conditionals as well.

One possible counterargument could be that the reported results do not bear on human reasoning because people were not asked to reason. However, it has been suggested that reasoning may not be a monolithic process but may, rather, include distinct phases, such as construction of the initial representation, inference, and search for counterexamples (see Rader \& Sloutsky, in press, for a discussion). The reported results may depict the initial representation of logical connectives, and there is some evidence demonstrating effects of initial representations on reasoning (Sloutsky \& Goldvarg, 1999).

Alternatively, a defender of syntactic theories could argue that the reported results do not bear on human reasoning because most "mental logic" schemas are procedural in nature and manifest themselves only during the on-line comprehension of discourse (Braine \& O'Brien, 1991; Lea, 1995; Lea et al., 1990). Therefore, according to this argument, off-line, explicit memory measures 
could not yield evidence for the operation of inference schemas. Finally, one could argue that inference schemas apply only to argument forms, and not to single propositions. One rejoinder is that because syntactic theories require people to represent accurately entire argument forms, they seem also to require people to represent accurately each proposition in an argument form. Second, syntactic theories do not predict, a priori, that inference schemas for some logical forms are more available in memory than those for others (see, e.g., Rips, 1994). Inference schemas should be activated by the appropriate input. Because the forms of conjunction, disjunction, and conditional should all be available, they should yield similar error rates in memory tasks. Instead, we found a systematic pattern in which conjunctions are favored. Semantic theories and the conjunctive bias hypothesis allow one to predict this pattern, instead of merely describing differences in difficulty after the fact. Thus, although the conjunctive bias may not decisively refute syntactic theories, it suggests that they are at the least incomplete.

We must consider two alternative explanations of the results. One possibility is that the base rate of conjunctions may be higher in everyday discourse than that of other propositional forms. Better memory for conjunctions may simply reflect base-rate differences in availability. This proposal is impossible to address cleanly, because no one, to the authors' knowledge, has tabulated the incidences of usage of various propositional forms in everyday discourse. However, the results from Experiment 3, in which unlearned propositions of all forms were overwhelmingly rejected, suggest that any such "frequency" effect is negligible. It should be noted, at any rate, that usage of various connectives, logical and others, is heavily determined by linguistic context and relevant prior knowledge (e.g., Byrne \& Johnson-Laird, 1992; Murray, 1997).

Another alternative explanation is the pragmatic argument that conjunctions are, in many cases, more acceptable than disjunctions, so that disjunctions may be subject to more distortion in memory. Specifically, and may be more acceptable than or in discourse, because propositions linked by or are less likely to satisfy the "common topic principle"; that is, a meaningful connection between the propositions often cannot be inferred. Propositions linked by and are more likely to satisfy this principle, because conjunctions can express some relationships, such as causal and temporal ones, that are not easily expressed with or (Lakoff, 1971; see also Politzer, 1986). A few memory studies, comparing propositions that violate this principle with others that do not, support the idea that common topic is important in memory for conjunctions and disjunctions (Fillenbaum, 1971, 1974a, 1974b).

However, pragmatic acceptability alone does not seem to predict memory performance. The sensibility results of Experiment 3 indicate that conjunctions are, in fact, more sensible than disjunctions and conditionals. When variance in sensibility is removed, however, conjunctions are still accepted more often than disjunctions and significantly more often than conditionals in the recognition task. The results of all three experiments seem to indicate that a conjunctive bias in representation persists beyond just a pragmatic preference for conjunctions visà-vis conditionals and disjunctions.

The finding of a conjunctive bias adds to our understanding of how people process logical connectives. Conjunctionsseem to be more accurately represented than disjunctions and conditionals in relatively abstract semantic contexts; nonconjunctive forms show a tendency to be converted to conjunctions. As we have described, this explanation is consistent with many empirical findings in reasoning. Other research, however, suggests that conjunctions seem to be less accurately represented in memory than are causal and adversative connectives such as because and but, respectively, and to play less of a role in comprehension (Caron, Micko, \& Thüring, 1988; Fletcher, Chrysler, van den Broek, Deaton, \& Bloom, 1995; Gernsbacher, 1997; Millis, Golding, \& Barker, 1995; Murray, 1997). None of these studies compared conjunctions with propositional forms involving other logical connectives and so did not address our claim that memory for conjunctions should be advantaged relative to memory for other propositional logical forms. Studying the representation and processing of connectives in a range of contexts and in a range of tasks will provide a more comprehensive picture. Such studies will also help clarify how well language maps onto logical reasoning competence; note that such a mapping is posited, in different ways, by semantic and syntactic theories. Finally, such research may yield a synthesis between the conjunctive bias hypothesis and other proposals (e.g., pragmatic arguments).

In the vein of examining the relationship between comprehension and reasoning processes, it should be noted that the conjunctive bias hypothesis is consistent with the discourse-processing notion that participants' representations of a text are rather limited to ideas explicitly stated, with only certain elaborative inferences being encoded (e.g., Kintsch, 1998; McKoon \& Ratcliff, 1992). The conjunctivebias is also consistent with the finding that conditionalinferences in comprehension may reflect initial representations of conditional premises that are logically incomplete, in that they are restricted to what is stated (Rader \& Sloutsky, in press). These inferences do not seem to reflect a mental logic, as has been claimed (Lea, 1995).

To summarize, the experiments reported here support the conjunctive bias hypothesis, indicating that conjunctions are better represented in memory and less likely to be distorted than are other propositional forms, such as disjunctions and conditionals. Whether these findings extend across a range of problem contexts and contents is still an empirical question. However, the reported results are an important step in our understanding of the representation and processing of statements that include these logical connectives. 


\section{REFERENCES}

BAuer, M. I., \& Johnson-Laird, P. N. (1993). How diagrams can improve reasoning. Psychological Science, 4, 372-378.

BEGG, I., \& Wickelgren, W. A. (1974). Retention functions for syntactic and lexical vs semantic information in sentence recognition memory. Memory \& Cognition, 2, 353-359.

Braine, M. D. S., \& O'Brien, D. P. (1991). A theory of if: A lexical entry, reasoning program, and pragmatic principles. Psychological Review, 98, 182-203.

Braine, M. D. S., \& O'Brien, D. P. (1998). Mental logic. Mahwah, NJ: Erlbaum.

Braine, M. D. S., Reiser, B. J., \& Rumain, B. (1984). Some empirical justification for a theory of natural propositional logic. In G. H. Bower (Ed.), The psychology of learning and motivation (Vol. 18, pp. 317-371). New York: Academic Press.

BY Rne, R. M. J., \& Johnson-LaIRD, P. N. (1992). The spontaneous use of propositional connectives. Quarterly Journal of Experimental Psychology, 45A, 89-110.

BY RnE, R. M. J., \& TAsso, A. (1999). Deductive reasoning with factual, possible, and counterfactual conditionals. Memory \& Cognition, 27, 726-740.

Caron, J., Micko, H. C., \& Thüring, M. (1988). Conjunctions and the recall of composite sentences. Journal of Memory \& Language, 27, 309-323.

Dosher, B. A. (1983). Relational information in sentence memory. Journal of Psycholinguistic Research, 12, 377-396.

Evans, J. S. (2000). What could and could not be a strategy in reasoning. In W. Schaeken, G. De Vooght, A. Vandierendonck, \& G. d'Ydewalle (Eds.), Deductive reasoning and strategies (pp. 1-22). Mahwah, NJ: Erlbaum.

Evans, J. S., Clibbens, J., \& Rood, B. (1995). Bias in conditional inference: Implications for mental models and mental logic. Quarterly Journal of Experimental Psychology, 48A, 644-670.

Evans, J. S., Handley, S. J., Harper, C. N. J., \& Johnson-Laird, P. N. (1999). Reasoning about necessity and possibility: A test of the mental model theory of deduction. Journal of Experimental Psychology: Learning, Memory, \& Cognition, 25, 1495-1513.

Evans, J. S., Newstead, S. E., \& Byrne, R. M. J. (1993). Human reasoning: The psychology of deduction. Hove, U.K.: Erlbaum.

Evans, J. S., \& Over, D. E. (1996). Rationality and reasoning. Hove, U.K.: Erlbaum.

Fillenbaum, S. (1971). On coping with ordered and unordered conjunctive sentences. Journal of Experimental Psychology, 87, 93-98.

Fillenbaum, S. (1974a). Or: Some uses. Journal of Experimental Psychology, 103, 913-921.

Fillenbaum, S. (1974b). Pragmatic normalization: Further results for some conjunctive and disjunctive sentences. Journal of Experimental Psychology, 102, 574-578.

Fletcher, C. R., Chrysler, S. T., van den Broek, P., Deaton, J. A. \& Bloom, C. P. (1995). The role of co-occurrence, coreference, and causality in the coherence of conjoined sentences. In R. F. Lorch \& E. J. O'Brien (Eds.), Sources of coherence in reading (pp. 203-218). Hillsdale, NJ: Erlbaum.

Gernsbacher, M. A. (1997). Coherence cues mapping during com- prehension. In J. Costermans \& M. Fayol (Eds.), Processing interclausal relationships: Studies in the production and comprehension of text (pp. 3-21). Mahwah, NJ: Erlbaum.

Johnson-Laird, P. N. (1999). Deductive reasoning. Annual Review of Psychology, 50, 109-135.

Johnson-Laird, P. N., \& Byrne, R. M. J. (1991). Deduction. Hove, U.K.: Erlbaum.

Johnson-Laird, P. N., Byrne, R. M. J., \& Schaeken, W. (1992). Propositional reasoning by model. Psychological Review, 99, 418-439.

Johnson-Laird, P. N., SAVARY, F., \& Bucciarelli, M. (2000). Strategies and tactics in reasoning. In W. Schaeken, G. De Vooght, A. Vandierendonck, \& G. d'Ydewalle (Eds.), Deductive reasoning and strategies (pp. 209-240). Mahwah, NJ: Erlbaum.

KINTSCH, W. (1998). Comprehension: A paradigm for cognition. Cambridge: Cambridge University Press.

Klauer, K. C., \& Oberauer, K. (1995). Testing the mental model theory of propositional reasoning. Quarterly Journal of Experimental Psychology, 48A, 671-687.

LAKOFF, R. (1971). If's, and's, and but's about conjunction. In C. J. Fillmore \& D. T. Langendoen (Eds.), Studies in linguistic semantics (pp. 114-149). New York: Holt, Rinehart \& Winston.

LEA, R. B. (1995). On-line evidence for elaborative logical inferences in text. Journal of Experimental Psychology: Learning, Memory, \& Cognition, 21, 1469-1482.

Lea, R. B., O'Brien, D. P., Fisch, S. M., Noveck, I. A., \& Braine, M. D. S. (1990). Predicting propositional logic inferences in text comprehension. Journal of Memory \& Language, 29, 361-387.

McKoon, G., \& Ratcliff, R. (1992). Inference during reading. Psychological Review, 99, 440-466.

Millis, K. K., Golding, J. M., \& Barker, G. (1995). Causal connectives increase inference generation. Discourse Processes, 20, 29 49.

Murray, J. D. (1997). Connectives and narrative text: The role of continuity. Memory \& Cognition, 25, 227-236.

Politzer, G. (1986). Laws of language use and formal logic. Journal of Psycholinguistic Research, 15, 47-92.

Polk, T. A., \& Newell, A. (1995). Deduction as verbal reasoning. Psychological Review, 102, 533-566.

RAder, A. W., \& SLOutSKy, V. S. (in press). Processing of logically valid and logically invalid conditional inferences in discourse comprehension. Journal of Experimental Psychology: Learning, Memory, \& Cognition.

RIPS, L. (1994). The psychology of proof: Deductive reasoning in human thinking. Cambridge, MA: MIT Press.

SACHS, J. S. (1974). Memory in reading and listening to discourse. Memory \& Cognition, 2, 95-100.

Schmerling, S. F. (1975). Asymmetric conjunction and rules of conversation. In P. Cole \& J. L. Morgan (Eds.), Syntax and semantics. Vol. 3. Speech acts (pp. 211-231). New York: Academic Press.

SLOUTSKY, V. M., \& GoldVARG, Y. (1999). Effects of externalization on representation of indeterminate problems. In M. Hahn \& S. Stones (Eds.), Proceedings of the XXI Annual Conference of the Cognitive Science Society (pp. 695-700). Mahwah, NJ: Erlbaum.

SuperLab Pro (Version 1.05) (1997). [Computer software]. Phoenix, AZ: Cedrus Corporation.

\section{APPENDIX A \\ Stimulus Propositions of Experiment 1}

\begin{tabular}{cll}
\hline & \multicolumn{2}{c}{ Propositional Form } \\
\cline { 2 - 3 } No. & \multicolumn{1}{c}{ Conjunctions } & \multicolumn{1}{c}{ Disjunctions } \\
\hline 1 & walks home and bakes bread & wears shoes or climbs mountains \\
2 & throws stones and writes letters & watches birds or breaks pencils \\
3 & raises dogs and drives a car & reads books or fears snakes \\
\hline
\end{tabular}

Note-Each proposition began with This professor (omitted from table entries for brevity). 
APPENDIX B

Original Propositions of Experiment 2

\begin{tabular}{|c|c|c|c|}
\hline No. & Conjunctions* & Disjunctions* & Conditionals $\dagger$ \\
\hline 1 & $\begin{array}{l}\text { takes medicine and he } \\
\text { likes the zoo }\end{array}$ & $\begin{array}{l}\text { writes letters or he eats } \\
\text { potatoes }\end{array}$ & $\begin{array}{l}\text { If ... plays baseball then he } \\
\text { is a secretary }\end{array}$ \\
\hline 2 & $\begin{array}{l}\text { trains dolphins and he } \\
\text { bakes bread }\end{array}$ & $\begin{array}{l}\text { repairs dishwashers or he } \\
\text { collects stamps }\end{array}$ & $\begin{array}{l}\text { If } \ldots \text { grows flowers then he } \\
\text { misses the ocean }\end{array}$ \\
\hline 3 & $\begin{array}{l}\text { goes fishing and he wears } \\
\text { shoes }\end{array}$ & $\begin{array}{l}\text { hates dentists or he uses a } \\
\text { typewriter }\end{array}$ & $\begin{array}{l}\text { If ... mows the grass then } \\
\text { he loves the beach }\end{array}$ \\
\hline 5 & $\begin{array}{l}\text { has nightmares and he } \\
\text { breaks speed limits }\end{array}$ & $\begin{array}{l}\text { runs a company or he goes } \\
\text { camping }\end{array}$ & $\begin{array}{l}\text { If ... climbs mountains then } \\
\text { he places bets }\end{array}$ \\
\hline 6 & $\begin{array}{l}\text { fears snakes and he coaches } \\
\text { soccer }\end{array}$ & $\begin{array}{l}\text { sells cars or he avoids } \\
\text { butter }\end{array}$ & $\begin{array}{l}\text { If ... watches } \mathrm{TV} \text { then he } \\
\text { rides horses }\end{array}$ \\
\hline 7 & $\begin{array}{l}\text { irons his clothes and he } \\
\text { cleans the shower }\end{array}$ & $\begin{array}{l}\text { teaches school or he fails } \\
\text { physicals }\end{array}$ & $\begin{array}{l}\text { If } \ldots \text { forgets birthdays then } \\
\text { he listens to songs }\end{array}$ \\
\hline 10 & $\begin{array}{l}\text { drinks beer and he builds } \\
\text { houses }\end{array}$ & $\begin{array}{l}\text { reads newspapers or he } \\
\text { joins clubs }\end{array}$ & $\begin{array}{l}\text { If } \ldots \text { cleans his office then } \\
\text { he wears spectacles }\end{array}$ \\
\hline 11 & $\begin{array}{l}\text { attends school and he likes } \\
\text { hotels }\end{array}$ & grows corn or he tells jokes & $\begin{array}{l}\text { If } \ldots \text { demands perfection } \\
\text { then he collects wines }\end{array}$ \\
\hline 12 & $\begin{array}{l}\text { buys insurance and he } \\
\text { watches birds }\end{array}$ & $\begin{array}{l}\text { plays boardgames or he } \\
\text { goes to movies }\end{array}$ & $\begin{array}{l}\text { If ... tells lies then he } \\
\text { follows others }\end{array}$ \\
\hline 13 & $\begin{array}{l}\text { combs his hair and he edits } \\
\text { a newspaper }\end{array}$ & $\begin{array}{l}\text { sleeps all day or he buys } \\
\text { paintings }\end{array}$ & $\begin{array}{l}\text { If ... has a cat then he eats } \\
\text { pizza }\end{array}$ \\
\hline 14 & $\begin{array}{l}\text { designs houses and he } \\
\text { writes letters }\end{array}$ & $\begin{array}{l}\text { helps friends or he builds } \\
\text { tables }\end{array}$ & $\begin{array}{l}\text { If } \ldots \text { grows vegetables then } \\
\text { he owns a house }\end{array}$ \\
\hline 15 & $\begin{array}{l}\text { skips meetings and he } \\
\text { wears polyester }\end{array}$ & $\begin{array}{l}\text { states his opinions or he } \\
\text { uses maps }\end{array}$ & $\begin{array}{l}\text { If } \ldots \text { makes dinner then he } \\
\text { rides a bicycle }\end{array}$ \\
\hline
\end{tabular}

*Each description began with This professor (omitted from table entries for brevity). †The phrase this professor followed "If" in each description (omitted for brevity). 